\title{
Pediatric spinal perimedullary arteriovenous fistula
}

\author{
Fístula arteriovenosa perimedular espinhal pediátrica
}

Mauricio F. Villamar', Gulam Qutubuddin Khan', Valeria I. Naranjo', Abdulnasser Alhajeri²

A previously healthy 23-month-old girl presented with acute paraparesis and bilaterally upgoing toes. MRI revealed a spinal perimedullary arteriovenous fistula $(\mathrm{PMAVF})^{1}$ between T6 and the conus medullaris (Figures 1A-1B; 2A-2B).

Trans-arterial Onyx $^{\circledR}$ embolization ${ }^{2}$ was performed (Figure 2C). She had complete recovery post-therapy. Follow-up MRIs showed no recurrence of PMAVF (Figure 1C).
PMAVFs, or type IV arteriovenous malformations, are intradural spinal vascular abnormalities (in contrast to dural arteriovenous fistulas) that lack a nidus (as opposed to type II-III arteriovenous malformations $)^{2,3}$.

Asymptomatic PMAVFs are uncommon; most cause slowly progressive medullary/radicular signs, although symptoms can develop acutely ${ }^{1,4}$. When treated, PMAVFs typically have a more favorableprognosis than other spinal arteriovenous malformations ${ }^{1}$.
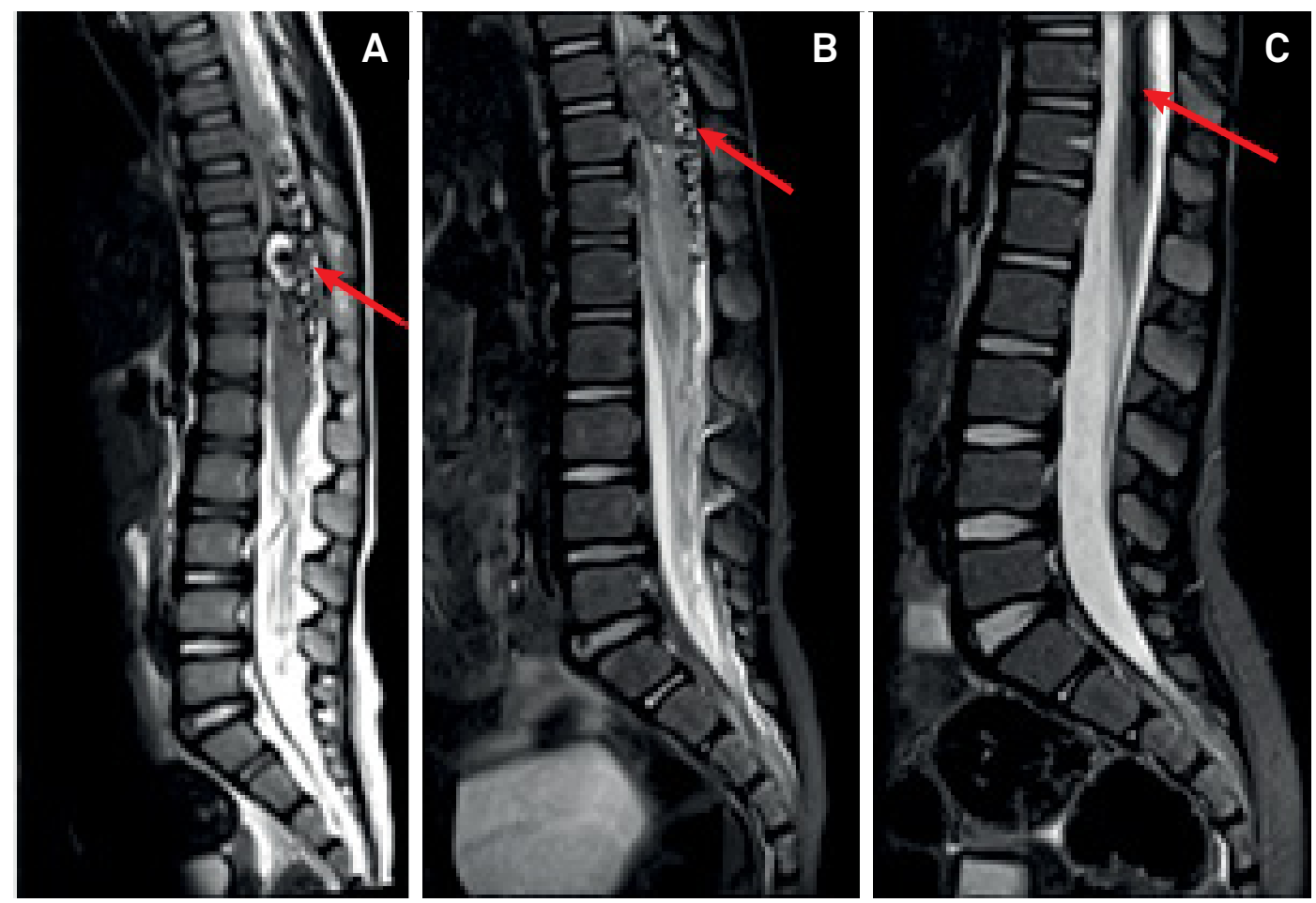

Figure 1. Spinal MRI. Focal area of hemorrhage at T9-10 with serpiginous signal void is seen on sagittal T2 (Panel A, arrow) and STIR sequences (Panel B, arrow), indicating PMAVF. Postembolization sagittal STIR revealed complete PMAVF resolution, with residual hemosiderin deposition from a prior hemorrhage (Panel C, arrow).

${ }^{1}$ University of Kentucky, Department of Neurology, Lexington, KY, USA;

${ }^{2}$ University of Kentucky, Departments of Radiology and Neurosurgery, Lexington, KY, USA.

Correspondence: Abdulnasser Alhajeri; Departments of Radiology and Neurosurgery, University of Kentucky; 800 Rose Street, Room HX-313B, Lexington, KY, USA 40536-0293; E-mail:nasser.alhajeri@uky.edu

Conflict of interest: There is no conflict of interest to declare.

Received 06 April 2018; Received in final form 22 May 2018; Accepted 29 May 2018. 

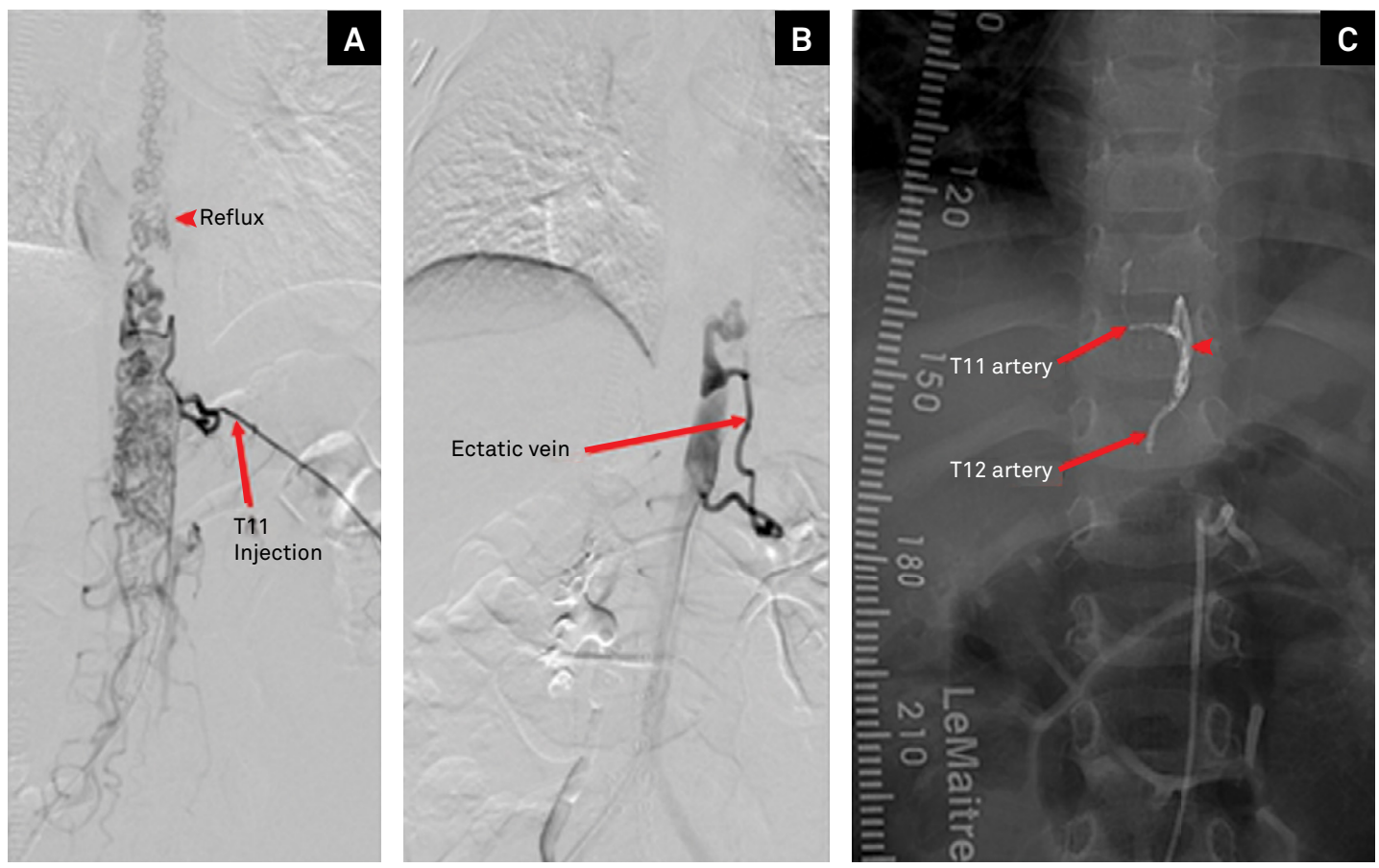

Figure 2. Spinal angiogram. Spinal angiogram demonstrated two spinal arteries (T11 and T12 arteries; Panels A and C, arrows) fistulating with a large ectatic vein (Panel B), with reflux into the spinal venous plexus from the conus into the upper thoracic region (Panel A, arrowhead). When T11 was injected, contrast would reflux from the fistula toward T12 (Panel B). Trans-arterial Ony ${ }^{\circledR}$ embolization through the T11 artery was performed. Postembolization with T11 intercostal artery injection shows Ony ${ }^{\circledR}$ cast within the fistula at the junction between the artery and the draining vein (Panel C, arrowhead).

\section{References}

1. Sure U, Wakat JP, Gatscher S, Becker R, Bien S,

Bertalanffy H. Spinal type IV arteriovenous malformations (perimedullary fistulas) in children.

Childs Nerv Syst. 2000 Aug;16(8):508-15. https://doi.org/10.1007/s003810000293

2. Phadke RV, Bhattacharyya A, Handique A, Jain K, Kuymar A, Singh V et al. Endovascular treatment in spinal perimedullary arteriovenous fistula. Interv Neuroradiol. 2014 Jun;20(3):357-67. https://doi.org/10.15274/INR-2014-10056
3. Rodesch G, Hurth M, Alvarez H, Tadie M, Lasjaunias P. Spinal cord intradural arteriovenous fistulae: anatomic, clinical, and therapeutic considerations in a series of 32 consecutive patients seen between 1981 and 2000 with emphasis on endovascular therapy. Neurosurgery 2005 Nov; 57(5):973-83. https://doi.org/10.1227/01.NEU.0000181314.94000.CD .

4. Cullen S, Krings T, Ozanne A, Alvarez H, Rodesch G, Lasjaunias P. Diagnosis and endovascular treatment of pediatric spinal arteriovenous shunts. Neuroimaging Clin N Am. 2007;17(2):207-21. https://doi.org/10.1016/j.nic.2007.02.004 